\title{
Awareness among Post-Graduate Students about Ergonomic Practice in Vidarbha Region
}

\author{
Srajan Hora ${ }^{1}$, Tanvi Jaiswal² ${ }^{2}$ Seema Sathe ${ }^{3}$ \\ ${ }^{1}$ SPDC, Sawangi, Wardha, Maharashtra, India. ${ }^{2}$ Department of Prosthodontics and Crown and Bridge, SPDC, \\ Sawangi, Wardha, Maharashtra, India. ${ }^{3}$ Department of Prosthodontics and Crown and Bridge, SPDC, \\ Sawangi, Wardha, Maharashtra, India.
}

\section{ABSTRACT}

\section{BACKGROUND}

In recent times ergonomics has become a popular term. The term has been used with most professions but increasingly in the dental profession. Dentistry is a profession in which all the dentists worldwide are commonly affected with health hazards like musculoskeletal disorders which hinders their clinical practice resulting in early retirements. So, to evaluate workplace efficiency and prevalence of musculoskeletal problems in practicing local dentists this study was planned. We wanted to assess the awareness about proper ergonomic practice among the postgraduate dental students in Vidarbha region.

\section{METHODS}

The study was undertaken at Sharad Pawar Dental College between 2018-2019. Study comprised of 50 post-graduate students. Each student was asked to fill selfadministered questionnaire regarding ergonomics. The questionnaire consisted of a total of 10 questions. Results were assessed accordingly.

\section{RESULTS}

Out of all the participating post-graduate students, $84 \%$ have knowledge of the term ergonomics and its applications in dental practice. 52\% of them responded positively to taking micro breaks while performing a procedure. $88 \%$ of them are aware of the posture related musculoskeletal disorders. $84 \%$ of them responded positively about experiencing symptoms during working. $68 \%$ of them responded positively about knowing some exercises to strengthen their back, shoulders or hands. $36 \%$ of the participants are practicing four handed dentistry.

\section{CONCLUSIONS}

Awareness about dental ergonomics can enable the post-graduate students and other dental practitioners to have a better work-life, and provide their patients with the quality of service they need.

\section{KEY WORDS}

Ergonomic Practice, Musculoskeletal Disorder, Dental Equipment, Posture, Working Environment
Corresponding Author:

Dr. Tanvi Jaiswal,

Department of Prosthodontics,

SPDC, Sawangi (M),

Wardha-442001, Maharashtra, India.

E-mail: tanvijaiswal90@gmail.com

DOI: $10.14260 /$ jemds/2020/61

Financial or Other Competing Interests: None.

How to Cite This Article:

Hora S, Jaiswal T, Sathe S. Awareness among post-graduate students about ergonomic practice in Vidarbha region. J. Evolution Med. Dent. Sci. 2020;9(05):271274, DOI: 10.14260/jemds/2020/61

Submission 12-11-2019,

Peer Review 12-01-2020,

Acceptance 18-01-2020,

Published 03-02-2020. 


\section{BACKGROUND}

Ergonomics evolves from a Greek word, 'ERGO' means 'Work' and 'NOMIC' means 'Natural law'; specifically, ergonomics is defined as relationship among the personnel, equipment, environment and designing of the working area. ${ }^{1}$ Ergonomics (or human factors) is the scientific discipline concerned with the understanding of interactions among humans and other elements of a system, and the profession that applies theory, principles, data and methods to design in order to optimize human well-being and overall system performance. Ergonomics implies the study and analysis of human capabilities and limitations during the professional work including anatomic and psychological aspects. The ergonomic elements in dentistry which must be discussed in relation to the occupational environment are the dental team positioning, the design of the working area, dental equipment and the collaboration between the dentist and the dental assistant within Four Handed Dentistry. Dentistry is a profession in which all the dentists worldwide are commonly affected with health hazard like musculoskeletal disorders which hinders their clinical practice resulting in early retirements. Dental personnel are at an increased risk of developing such disorders. According to WHO musculoskeletal disorder is define as a disorder of the muscles, tendons, peripheral nerves or vascular system not directly resulting from an acute and instantaneous event. Therefore, it is also known as work related musculoskeletal disorder. The main reason found for this disorder present among dentist is long working hours in inadequate posture. The past studies have proven that working in awkward posture results in muscular pain. Back pain $(70-90 \%)$ is considered the most common problem suffered by the dental operators followed by neck, shoulder, hand pain and several other disorders. It focuses on human ability in association to working environment. ${ }^{2}$ Applying ergonomics to the practice of dentistry not only could provide safety benefits but a practitioner might also improve performance objectives through greater productivity. One of the main goals of ergonomics in dentistry is to minimize the amount of physical and mental stress that sometimes occurs day to day in a dental practice, the pain associated with ergonomics could begin to appear at the beginning of their clinical practice as students and accompany them for the rest of their professional life. Dental field is a specialty in which all the dentists amongst world are very often afflicted with health hazard like musculoskeletal disorders which hampers their dental process and leads to early retirements from their workplace. ${ }^{3}$

Dentists having potential risk of being targeted by MSDs because of longevity in clinical hours \& uncertain postures. While doing a procedure, dentists try to manage the neutrality of their posture by applying undue pressure on their musculature leading to contraction of muscles which conclusively leads to the expansion of MSDs. Assorted postures leading to musculoskeletal stresses include: Strategy, Clear view of the oral structures, Complex equipment, comfort to the patient, handling instruments, index finger and the thumb used for grasping the instrument in the modified pen grasp forcefully, poorly structured small instruments, longer duration of procedures, contact stresses includes approaching instruments with narrow grips impinging the bone leading to inflammation and reduced blood flow, Psychosocial stresses, Continuous related repetitive movements. ${ }^{4}$ Therefore this survey was carried out to evaluate awareness among post-graduate students about proper ergonomic practice in Vidarbha region.

\section{METHODS}

It was a cross section questionnaire-based study conducted in our institution situated in Vidarbha region. Study comprised of 50 post-graduate students. Samples size was selected by using standard formula ie:- $\mathrm{N}=4^{*} \mathrm{p}^{*}(1-\mathrm{p}) / \mathrm{L}^{2}$. Ref:- Hima Batra et al ${ }^{5}$ Approximately 70 students approached amongst whom 50 were selected randomly by lottery method, Informed consent were taken for the study. The inclusions of samples are the postgraduate students of clinical departments. Our objective was to assess the awareness about ergonomic practice among the post-graduate dental students. Each student was asked to fill self-administered validated standard questionnaire regarding ergonomics. The questionnaire consisted of total 10 questions. The patient responses were assessed primarily in terms of frequency distribution of various "Yes/No" answers.

\section{Statistical Analysis}

Statistical analysis was performed by using descriptive and inferential statistics using z-test for single proportion and software used in the analysis was SPSS 22.0 version and $\mathrm{p}<0.05$ is considered as level of significance.

\section{RESULTS}

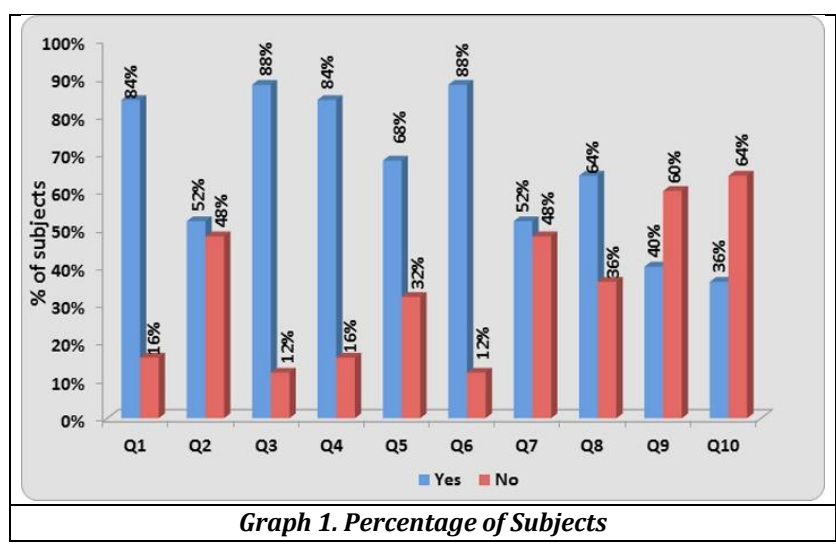

\begin{tabular}{|c|c|c|c|}
\hline Sl. No. & Question & Yes & No \\
\hline 1 & $\begin{array}{c}\text { Are you aware of the term 'Ergonomics' and its implications in } \\
\text { Dental practice? }\end{array}$ & $84 \%$ & $16 \%$ \\
\hline 2 & Do you take micro-breaks (2-5 min) during a procedure? & $52 \%$ & $48 \%$ \\
\hline 3 & Are you aware of posture related musculoskeletal disorders? & $88 \%$ & $12 \%$ \\
\hline 4 & $\begin{array}{c}\text { Have you experienced any symptoms in neck, shoulders, hands, } \\
\text { or back during working? }\end{array}$ & $84 \%$ & $16 \%$ \\
\hline 5 & $\begin{array}{c}\text { Do you know about any exercises to strengthen your back, } \\
\text { shoulders or hands? }\end{array}$ & $68 \%$ & $32 \%$ \\
\hline 6 & $\begin{array}{c}\text { Have you ever noticed that you practice with awkward } \\
\text { positions involving excessive bending of the neck, prolonged } \\
\text { sitting/standing? }\end{array}$ & $88 \%$ & $12 \%$ \\
\hline 7 & $\begin{array}{c}\text { Is there a constant vibration in the instruments/ handpiece you } \\
\text { are using? }\end{array}$ & $52 \%$ & $48 \%$ \\
\hline 8 & $\begin{array}{c}\text { Are you aware of magnification and visualization aids that may } \\
\text { help you ergonomically? }\end{array}$ & $64 \%$ & $36 \%$ \\
\hline 9 & Is the temperature of the working area comfortable for you? & $40 \%$ & $60 \%$ \\
\hline 10 & Do you practice four-handed dentistry? & $36 \%$ & $64 \%$ \\
\hline \multicolumn{3}{|c|}{ Table 1. Close Ended Questions } \\
\hline
\end{tabular}


It was observed that out of all the participating postgraduate students, $84 \%$ of them have the knowledge of term ergonomics and its applications in dental field. $52 \%$ of them responded positively to taking micro breaks while performing a procedure. $88 \%$ of them are aware of the posture related musculoskeletal disorders. $84 \%$ of them responded positively as to experiencing symptoms during working. $68 \%$ of them responded positively as to knowing about some exercises to strengthen their back, shoulders or hands. $88 \%$ of the participating subjects are known to practice with awkward positions involving excessive bending and sitting and/or standing. 52\% of them use hand pieces or instruments having a constant vibration. $64 \%$ of the participating subjects are aware of magnification and visualization aids that can help them ergonomically. $40 \%$ of the subjects feel that the temperature of the working area to which they are subjected daily is comfortable for them. 36\% of them are known to practice four handed dentistry.

\section{DISCUSSION}

Health professional courses are very prestigious in society whether it is Allopathy, Ayurveda, Homeopathy, Dentistry, Physiotherapy, and Nursing disciplines. The main aim of the health professional courses is to train students to become physicians who will promote the health of all people. Becoming physician is a very demanding commitment that bestows strong personal effects and shapes many life events. ${ }^{4}$

The present study is a survey to evaluate awareness among post-graduate students about proper ergonomic practice in Vidarbha region. Dentists are considered as one of the highest risk professionals for MSDs. The prolonged working hours, uncertain postures and high visual requirement make them prone to the development of MSDs. In present study $84 \%$ of postgraduate students have experienced musculoskeletal problems while performing patients work clinically which corresponds to other studies done on ergonomics. $84 \%$ of subjects shows awareness about ergonomics, this result was same as the study carried out by Batra et al. ${ }^{5}$ and higher count as compared to the studies done by Kanteshwari et al. and Gupta et al. which concludes only $50 \%$ of the respondents were familiar of ergonomics 6,7 and $59.6 \%$ in another study done by Gopinadh et al. ${ }^{8} 52 \%$ of students agree that they face problem of repetitive vibrations in the handpiece while working. Akesson et al in 2000 in their study noted that repetitive vibrations in handpiece lead to irritation of nerves leading to carpel tunnel syndrome due to harmful effects of these vibrations. The practice of four handed dentistry verified to be significant in reducing stress as complimented by Finkbeiner et al. $(2000,2001)^{9,10}$ in their studies. Although in a study done by Shetty et al. showed that only $27 \%$ of the dentists practiced four handed dentistry. ${ }^{11}$ which favors the similar results of our study i.e., only $36 \%$ of students practice four handed dentistry. This means more awareness regarding applications of ergonomics in MSDs is required. In present study only $40 \%$ of students agree that temperature in working area is comfortable. However, Lund ${ }^{12}$ stresses on maximum temperature and illumination of the working environment for good ergonomics.

\section{CONCLUSIONS}

Successful application of ergonomics assures high productivity and avoidance of illnesses and injuries. Unsuccessful application, on the other hand, can lead to work related MSDs. It is critical to seek prompt medical care for symptoms of ergonomic stress/detect risk factors. We should start incorporating good ergonomics in our dental practice and should be able to see the results from day 1 in the form of less fatigue and increased efficiency. Majority of students are aware of ergonomic practice and its implications. They also noticed that because of practice with uncertain positions involving excessive bending of the neck, prolonged sitting/standing, they are facing musculoskeletal problems, but still majority of them are not practicing four handed dentistry and not following its applications \& other factors which help to facilitate its reduction. One should incorporate good ergonomic practices during clinical work and achieve best results in the form of less fatigue and increased efficiency. It is of vital importance to promote occupational health training and prevention programs regarding ergonomic postures. Attention should be given to changing destructive postural habits, and selecting equipment conducive to good posture.

\section{REFERENCES}

[1] Ahmed S, Ahmed N, Faruqui S. Assessment of ergonomic decencies: at work dentists. J Interdiscipl Med Dent Sci 2016;4:196.

[2] Yadav N, Gupta H, Pradeep K, et al. Ergonomics: the Xfactor for wellness in dentistry. International Journal of Applied Dental Sciences 2015;1 (4):128-32.

[3] Valachi B, Valachi K. Mechanisms leading to musculoskeletal disorders in dentistry. J Am Dent Assoc 2003;134 (10):1344-50.

[4] Sarode RD, Tendolkar VD. Psychological pain as predictor of impulse control among BAMS new entrants: a correlation study. Journal of Datta Meghe Institute of Medical Sciences University 2018;13 (4):171-4.

[5] Batra H, Rajvanshi H, Anshul K, et al. An estimation of awareness among practicing dentists about proper ergonomic practice and its implications in Delhi National Capital Region. Int J Sci Stud 2015;3 (7):70-5.

[6] Kanteshwari K, Sridhar R, Mishra AK, et al. Correlation of awareness and practice of working postures with prevalence of musculoskeletal disorders among dental professionals. Gen Dent 2011;59 (6):476-83.

[7] Gupta AA, Mhaske SA, Ahmad MA, et al. Ergonomic microscope: need of the hour. J Clin Diagn Res 2015;9 (5):ZC62-5.

[8] Gopinadh A, Devi KNN, Chiramana S, et al. Ergonomics and musculoskeletal disorder: as an occupational hazard in dentistry. J Contemp Dent Pract 2013;14 (2):299-303.

[9] Finkbeiner BL. Four-handed dentistry revisited. J Contemp Dent Pract 2000;1 (4):74-86.

[10] Finkbeiner BL. Selecting equipment for the ergonomic four-handed dental practice. J Contemp Dent Pract 2001;2 (4):44-52. 
[11] Shetty A, Ananya D, Hegde MN, et al. Prevalence of musculoskeletal disorders among dental surgeons in different specialities. Int J Sci Res 2014;3 (3):2277-8179.
[12] Lund AE. Have you or a member of your staff ever sustained an injury that is unequivocally related to the provision of dental care? J Am Dent Assoc 2001;132 (3):284. 